\title{
Research on the Challenges and Specific Countermeasures of Financial Sharing to Enterprise Financial Personnel
}

\author{
Chenyan Liu ${ }^{1, \mathrm{a}}$ \\ ${ }^{1}$ Jiangxi Vocational Technical College of Industry \& Trade, Jiangxi,Nanchang330038 \\ a739960103@gq.com

\begin{abstract}
With the advent of the information age, many emerging science and technology have become the management technology of enterprise finance. Enterprises can also establish their own financial shared service platform, improve management efficiency and strengthen financial security. At present, there will be some difficulties and problems in the mode of Financial Sharing and the current situation of the development of financial sharing. The emergence of these problems is a great impact and challenge for enterprise financial personnel. It is necessary to analyze the specific phenomenon of the actual enterprise sharing mode, and elaborate the existing problems and the specific measures of the dilemma.
\end{abstract}

Keywords: financial sharing, Enterprise financial personnel, Internet big data

\section{财务共享对企业财务人员的挑战与具体对策研究}

刘陈艳 ${ }^{1, a}$

${ }^{1}$ 江西工业贸易职业技术学院 江西 南昌 330038

a739960103@qq.com

摘要:

信息时代的来临，让许多新兴的咯科学技术成为了企业财务的管理技术，企业也可以对自身财务进 行共享服务平台的建立提高管理效率的同时，也加强了财务的安全性。目前财务共享模式以及财务 共享发展的现状都会存在一些困境和问题。这些问题的出现对于企业财务人员来说是一种巨大的冲 击和挑战, 需要对实际的企业共享模式的具体现象进行分析, 把存在的问题以及困境的具体措施进 行相应的阐述。

关键词: 财务共享; 企业财务人员; 互联网大数据

\section{1 对企业财务共享发展现状}

\section{1 企业现状}

财务共享主要是针对互联网大数据平台之中的 财务会计知识进行的信息资源的共享。在大数据平台 下，更多依托的是企业之间的数据交流共享，针对企 业的组织以及企业的业务发展规律不断的进行企业
财务资源的整合使得企业在运营的过程之中更加的 规范化和制度化。强化企业财务运营成本的低消耗、 帮助企业创造最大化的价值。在大数据平台下， ${ }^{[1]}$ 通 过客户以及企业之间的财务管理模式可以使得财务 管理以及财务分享更加的在技术创新的基础上不断 的发展成为企业发展的新模式。与此同时, 很多大型 企业都在不断的整合信息管理话平台，让企业建立信 
息处理系统，从而帮助企业在大数据平台下不断的进 行优质服务的提供, 帮助企业建立核心竞争力。[2]

\section{2 管理人员发展现状}

财务共享条件下，企业的财务管理人员也在不断 的发展过程之中面临着新的基于和新的挑战，企业财 务会计管理人员应该在做好自身发展工作的同时不 断的学习新的财务会计管理知识, 提高自身的综合素 质， ${ }^{[3]}$ 让自己可以在大数据管理平台之中灵活的运用 知识以及系统检索能力, 不断的帮助企业进行风险的 规避。在大数据平台下，对于财务会计管理人员需要 不断的进行业务能力的提升。企业财务人员应该紧紧 抓住互联网大数据时代的发展机遇, 进一步做好财务 管理工作和业务能力的提升, 让自身的素养可以在财 务管理之中得到锻炼, 不断的将自己培养成为一个合 格的财务会计管理工作者。 ${ }^{[4]}$

\section{2 财务共享对企业财务人员的挑战}

\section{1 对企业财务人员工作岗位的挑战}

对于当前财务报表模式的实施下，企业内部的财 务人员自我定位角色将会发生一些变化, 这种变化主 要体现在企业的业务活动产生大量的财务数据以后, 将直接通往网络终端, 通过安全程序进行扫描以后, 传输到财务共享平台上进行自动化处理。 ${ }^{[5]}$ 而对于企 业财务人员来说，他们将不会在第一时间与一线业务 员和实际经营业务活动进行接触, 这种机会将会大大 减少，而会更多的去面临各种财务数据的分析和收集。 [6]

对于企业来说, 大量的经营信息一般都储存在财 务数据当中, 所以财务人员就需要对财务数据信息进 行角色上的转变, ${ }^{[7]}$ 否则将难以把财务数据信息和企 业的经营业务活动融合发展起来, 并且会大大的影响 财务管理与会计核算工作的发展。对于财务管理人员 来说, 财务共享模式的实施以及实施条件下的各种工 作都会存在一定的挑战, 所以如果自我不进行角色的 转变以及理念的更新, 学习新知识和方法, 就难以在 当前的互联网时代下进行财务共享模式的工作。 ${ }^{[8]}$

\section{2 对企业财务人员工作职能的挑战}

传统的会计人员工作内容以及职能将会十分重 要, 而在新兴的财务共享模式下, 财务会计人员在工 作上的职能将会逐渐开始减缓, 而更重要的是财务会 计人员的方向将会转移到管理工作方向。 ${ }^{[9]}$ 针对财务 目标模式的发展企业就需要对原本的财务会计组织 机构进行相应的更新, 从而适应财务共享的需要和发 展, 从根本上去将会计人员的人数进行减少, 让留下 的会计人员了解自身工作职能上的转变。

同时企业财务共享平台还需要拥有一批专业性 强知识层面广告综合素质高以及拥有远大的财务战
略思维的高质量财务会计人员, 这种优秀的会计人员 能够打破原本和人员的工作职能, 更多的走向管理公 布的领域管理会计能够在企业的经营和活动的管理 中起到十分重要的作用。 ${ }^{[10]}$

这一类会计人员能够在经营管理的过程当中，区 域财务数据进行综合整理, 然后通过分类进行相应的 分析, 从而把数据进行整体上的整合, 然后还可以将 财务管理过程中有价值的财务数据进行及时处理和 整理, 然后上报于管理层, 无论是事前事中还是事后, 倘若在整理数据的过程中发现相应的风险问题, 也可 以及时向上级汇报，然后说出相应的原因以及防指财 务风险的具体措施, 极大程度上提高了整体的工作效 率, 还可以保障企业的财务风险可控性, 这也是为什 么财务共享模式下企业会计人员的重要性。

\section{3 对企业财务人员自我认知的挑战}

对于企业财务人员来说，在传统的财务管理模式 当中, 财务人员在企业内部的职能与工作往往都具有 单一性, 这种单一性主要体现在工作岗位是固定的, 导致工作内容比较单一, 以及财务人员每个人的分工 较为明确, 因此就很大程度上限制了企业财务人员的 思维发展以及自我认识上的限制, 其根本上主要在于 大部分的财务人员都只是想完成自身的本职工作，而 并不会对相应的企业管理经营以及决策有一定的了 解和关心, 这就导致整体的企业人员没有太多的集体 意识。 ${ }^{[1]}$

针对这样的情况, 在财务共享模式实施以后, 企 业财务人员从角色上就发生了根本上的改变, 无论是 财务工作的要求和重点, 还是说财务人员自身从自我 认识都存在了一些变化, 这些变化对于企业财务人员 来说, 是一种真正意义上的挑战。所以在该模式当下 针对新的财务工作条件, 财务人员就需要对自身的工 作定位进行相应的学习, 在了解自身并不是为了做好 原本的本职工作以后而去接触新的领域以及新的工 作要求, 还有互联网技术在财务管理工作中的运用, 财务人员该怎样去进行改变等等。 ${ }^{[12]}$

\section{3 财务共享对企业财务人员迎接挑战的对策}

企业建立财务共享服务平台是大数据时代发展 下面企业财务会计管理的必然趋势，在企业的财务会 计管理之中, 应该不断的利用大数据管理平台进行企 业业务的发展与壮大, 企业应该在大数据技术发展之 中, ${ }^{[13]}$ 利用大数据不断的进行企业风险能力的规范和 自我控制能力的提升。

企业只有在不断的提高自身的专业胜任能力, 才 可以在未来的创新能力发展过程之中取得先机。

\section{1 提高企业财务人员的创新能力}

对于原本的财务管理模式来说，财务人员自我能 够在工作内容上就能了解到是反复性的机械性工作, 
这种单一性不仅仅只是体现在工作流程上，而是流程 以及内容还有发展思维上都存在，对于财务人员来说， 就是需要完成工作岗位上的职能, 就不需要去对财务 相应的工作进行创新，而且整体上的难度并不存在。 [14]

近几年互联网在各大领域中进行普及和运用以 后，企业也才是重视自身的财务管理工作，进行相应 的引入和更新, 因此就出现了建立财务共享服务平台 的现象，这种平台以及财务共享模式的出现，但企业 开始重视财务人员的要求和标准, 在这样的情况下, 财务人员就需要去对自身的观念进行更改, 了解到当 下企业的管理模式中自我的定位，同时还需要去提高 和拓宽自身的自我认识以及综合素质, 企业人员只有 自身去跟随时代的步伐, 才能够更好的融入到企业建 立的财务共享服务平台当中。 ${ }^{[15]}$

在财务共享模式中, 每一个财务人员都必须在之 前的基础上提升综合业务素质以及专业胜任能力, 才 能够成为真正意义上的新型财务人员, 只有这样才能 够在企业的财务工作中得到肯定，而且财务人员还需 要去了解企业财务共享的要求和标准，根据不同的等 级和层面以及企业人员的培训要求来进行自我提升, 只有这样才能够得到企业的重视, 财务人员才可以在 未来企业的发展过程中发挥自我的潜能。

\section{2 企业财务人员要科学规划自己的未来}

在信息化时代发展的背景下，企业开始对财务共 享模式进行运用, 但是企业在对财务共享平台和模式 进行具体建设和运营的过程中, 就需要大量的优秀人 才来对每一个层次进行填充。因此企业就会对财务人 员进行工作上的划分, 这种划分往往存在精细化和城 市化的特点, 也对财务人员个体有了更高的专业能力 要求与标准。

现存的大部分企业人员都需要在这个时候考虑 到时代发展的机遇, 要从自身的认知层面出发去对未 来的财务管理工作进行相应的规划, 只有在了解企业 在信息化时代下发展后存在的各种专业技术，才能够 真正意义上的去把自身的综合素质提高，让自己能够 在未来的财务共享模式当中有着更高的竞争力, 使得 能够更加稳定地在企业内部进行工作和发展。针对财 务人员如何适应新型财务共享管理模式, 就可以从以 下几个问题上出发。

首先财务人员必须对自身的专业能力进行评估, 弥补自身的缺点, 而发挥自身的优势。其次, 财务人 员在对自身的优点和缺点进行了解以后, 就需要去制 定相应的学习计划, 严格按照学习计划去对自身的综 合素质进行提升, 不仅需要对书面学习和实践进行结 合, 还需要从线上线下进行相互互补。在当前互联网 时代下, 也需要去重视沟通和学习能力, 还需要向那 些具有较强专业性的财务人员进行学习, 必须在内心 当中树立一个, 如果自我不提升将会在未来岗位没有 工作的想法。

\section{3 企业财务人员要积极转型}

企业的管理模式在进行相应的转变, 用企业内部 的财务人员, 就更需要去对自身进行相应的转型配合 工作的转型, 成为新兴的管理会计人员, 不仅仅能够 满足企业在进行财务共享模式下的需求, 还可以让自 身在观念上产生转变, 拓宽自身的自我认识和思维创 造能力。企业财务人员还需要了解到财务共享模式下, 对于工作上的要求和标准将逐渐提高, 那么在未来的 管理工作当中，企业的财务人员将会有着相应的重要 作用, 也就意味着财务人员将会在企业未来的发展中 有着巨大的发展空间。

因此企业的财务人员就需要去主动接受和接触 财务共享模式, 只有这样才能够更好的去了解新的工 作岗位和工作理念, 能够让自身能够在工作岗位上的 转变中, 不存在一定的不适应性, 这就十分考验企业 财务人员在转型过程中能否将自身的思维进行转变, 同时还需要去了解财务共享工作的要求和标准, 让自 身进行各种思维职能上的知识进行学习, 才能够真正 意义上去胜任财务管理和会计核算升级工作, 才能够 在财务管理工作中表现出自身的价值。

对于企业来说，每一位合格的新型财务人员首先 就必须对未来的企业进行相应的规划, 而且需要在了 解自身未来发展的定位当中, 去科学地进行职业规划, 让自身始终都能够了解到企业的财务工作方向, 只有 这样才能够真正意义上的适应财务共享模式下企业 经营管理的工作职能转变。

\section{4. 结论}

总而言之，财务共享对于企业财务人员的影响是 巨大的，这不仅仅是一种挑战，对于企业财务人员来 说, 也需要对自身进行相应的定位和思维上的转变, 无论是对于企业来说还是企业财务人员来说这种转 变都是向上发展的。因此财务共享将成为企业财务人 员工作责任上转变的重要因素, 也正是因为财务共享 的出现, 让财务人员就对自身未来就需要有一定的规 划, 而不是像传统一样去做机械性的反复性工作, 让 那些原本的企业财务人员更好的进行思维上的创新, 企业也可以更加灵活的去对各种活动策划进行多方 面的决策导入, 促进企业在未来市场当中的发展。

\section{REFERENCES}

[1] Jie Maohua, Chao gejiletu, Jiao shoubin. Ways to improve the quality and ability of enterprise financial personnel in management transformation -- a case study based on Kaisheng biological company $[\mathrm{J}]$. Management case study and review, 2016, 9 (1): 65-81

[2] Liang Xiaozhen. On the career planning of financial personnel after Financial Sharing Service in foreign-funded enterprises -- Based on the 
management practice of group a [J]. Contemporary accounting, 2019, 0 (6): 115-116

[3] Zhou Yiyu, Bian qiurui, song Shuhong. Research on the construction effect and sustainable operation of Financial Sharing Center -- Taking Suning Tesco Group Co., Ltd. as an example [J]. China's collective economy, 2020 (36): 131-133

[4] Wang Chenqi, Zhou fan, Yang Hua, Wang JIhang. The role of financial integration system in the transformation of enterprise financial management functions -- Taking ZJ group as an example [J]. International business accounting, 2020 (7): 54-56

[5] Chen Chen, Zhuo Ziqi, Qiao Li, Zhang Junbo. Discussion on Regional Financial Sharing Model -Taking the "parallel operation of Finance and accounting" of CCCC second navigation bureau as an example [J]. Financial and accounting communication: Shang, 2019, 0 (12): 6-10

[6] Chen Jun. thoughts on the construction of Financial Sharing Center of local government financing platform companies -- from the perspective of transformation risk response plan [J]. China management informatization, 2018, 21 (19): 30-32

[7] Zhu Weidong, Li Shouzhu. Value analysis of Financial Shared Service Model from the perspective of financial strategy -- Taking Shandong Luhua group as an example [J]. Friends of accounting, 2018, 0 (17): 117-120

[8] Ye Huidan. The optimization of accounting information in manufacturing industry group under the "Internet plus" environment: Based on the perspective of Financial Shared Services [J]. accounting Communications: 2017, 0 (7): 109 112.)

[9] Wang Wei, Jing Caiyun. Research on enterprise financial sharing business process reengineering in the era of "great wisdom moving to cloud" -Taking the Accounts Payable process of Changhong Financial Sharing Center as an example [J]. Business accounting, 2016, 0 (20): 41-43

[10] Thursday new, Zhan Yanling, Tong Hongbing, Zhou Yuzhen, Lu Ming, Tao Lei, Li Dandan. Construction of Financial Sharing Center with integrated management and control of industry, finance and taxation [J]. Management of state owned enterprises, 2019, 0 (11): 80-88

[11] Jie Maohua, Chao gejiletu, Jiao shoubin. Ways to improve the quality and ability of enterprise financial personnel in management transformation -- a case study based on Kaisheng biological company [J]. Management case study and review, 2016, 9 (1): 65-81

[12] Dai Lu, Zhi Xiaoqiang. Exclusion effect, subsequent changes and influencing factors of enterprises introducing management accounting methods -- a case study based on the situation of state-owned enterprises [J]. Nankai management review, 2015, 18 (2): 103-114

[13] Han Xiaohong. Where is the future of enterprise financial management under the background of "Internet + " [J]. Chinese Journal of multimedia and network teaching (zhongxunjian), 2019, (12). 184-186

[14] Wu Xingmei. Research on financial management innovation of small and medium-sized enterprises in Fujian under the background of "Internet +" industrial integration [J]. Rural economy and technology, 2019, (24). $103 \sim 104$

[15] Zhang Jide, Liao Wei, Zhang Rongwu. The impact of ordinary investors' attention on the volume and price of stock market transactions -- An Empirical Study Based on Baidu Index [J]. Accounting research, 2014, (8). 52-59

[16] Li Peilin, Luo Weihua, Cai lin'e. adjusting measures to local conditions and making management accounting flourish everywhere -- Investigation and Reflection on the implementation of management accounting in iron and steel enterprises [J]. Metallurgical finance and accounting, 2015,07:18-23 